\title{
VARIABILIDADE ESPACIAL DA PLANTA DANINHA AZEVÉM EM CULTIVO DE TRIGO UTILIZANDO DIFERENTES MALHAS AMOSTRAIS
}

\author{
Luan Pierre Pott ${ }^{*}$, Telmo Jorge Carneiro Amado ${ }^{2}$, Nelson Diehl Kruse ${ }^{3}$, Lúcio de Paula Amaral ${ }^{2}$, Geovane Boschmann Reimche ${ }^{4}$, \\ Tiago De Gregori Teixeira ${ }^{4}$, Darlan Preuss 5 \\ 1 Programa de Pós-Graduação em Engenharia Agrícola, Universidade Federal de Santa Maria, 97105-900, Santa Maria, Brasil. \\ 2 Programa de Pós-Graduação em Agricultura de Precisão, Universidade Federal de Santa Maria, 97105-900, Santa Maria, Brasil. \\ 3 Departamento de Fitotecnia, Universidade Federal de Santa Maria, 97105-900, Santa Maria, Brasil. \\ 4 Programa de Pós-Graduação em Ciência do Solo, Universidade Federal de Santa Maria, 97105-900, Santa Maria, Brasil. \\ 5 Engenheiro Agrônomo, Rural Sul Consultoria Agrícola, 96990-000, Estrela Velha, Brasil.
}

*E-mail:Luanpierrepott@hotmail.com

\section{RESUMO}

Ao longo dos últimos anos a principal planta daninha da cultura do trigo tem sido o azevém, a qual infesta lavouras e compete com a cultura por recursos naturais. O controle das plantas daninhas, de forma geral, é realizado de forma indiscriminada, não levando em consideração sua variabilidade espacial. Uma forma para realizar o levantamento das plantas daninhas de forma precisa é utilizando malhas amostrais. O objetivo deste trabalho foi avaliar a variabilidade espacial da distribuição da planta daninha azevém com diferentes tamanhos de malhas amostrais. Foram geradas cinco malhas amostrais com dimensões de 6,125 x 6,125 m, 12,5 x 12,5 m, 25 x $25 \mathrm{~m}$, 50 x $50 \mathrm{~m}$, e 100 x $100 \mathrm{~m}$. A avaliação de levantamento da população da planta daninha azevém foi realizada com o auxílio de quadrados amostrais metálicos, quando a cultura do trigo se apresentava no início do afilhamento. Malhas amostrais de 6,125 x 6,125 m, 12,5 x $12,5 \mathrm{~m}, 25$ × $25 \mathrm{~m}$ e $50 \times 50 \mathrm{~m}$, com exceção da malha $100 \times 100 \mathrm{~m}$, apresentaram elevado coeficiente de variação, o que caracteriza a heterogeneidade de sua presença e grau de infestação na área. Pode-se concluir que a medida que reduz o tamanho da malha amostral aumenta a precisão na caracterização da variabilidade espacial de densidade da planta daninha, possibilitando a confecção de mapas temáticos da infestação de azevém com precisão.

Palavras-chave: Agricultura de precisão. Geoestatística. Mapas temáticos.

\section{Introdução}

O trigo [Triticum aestivum (L.)] é uma das culturas agrícolas com maior volume de produção mundial, juntamente com o milho e o arroz [1]. Sua importância é dada pela utilização do grão em diversas dietas, principalmente na humana, na maioria dos países, desempenhando papel nutricional, econômico e social.

Um dos fatores bióticos que afetam a produção da cultura do trigo é a interferência de plantas daninhas. Essa interferência causa grandes perdas em produtividade ao trigo, gerando aumento nos custos de produção, com a utilização de herbicidas, o que torna a cultura cada vez menos atraente economicamente [2].

São várias as plantas daninhas que ocasionam perdas na cultura do trigo, no entanto, nos últimos anos, o azevém [Lolium multiflorum (Lam.)] tornou-se uma das principais plantas daninhas da cultura, visto que vem sendo amplamente cultivada na região Sul do Brasil como planta de cobertura e pastagens de inverno. Esta situação tem acarretado maior banco de sementes no solo, juntamente com a facilidade de dispersão de sementes e sua resistência a herbicidas, principalmente ao glifosato [3].

O controle de plantas daninhas com a utilização de herbicidas é o manejo que mais incrementa o custo de produção das culturas agrícolas. Uma alternativa para diminuir este custo é realizá-la de forma dirigida. Para tanto, é necessário conhecer a variabilidade espacial de plantas daninhas para sua prescrição.

As ferramentas de agricultura de precisão tornam possível realizar o levantamento da variabilidade espacial da ocorrência, distribuição e densidade de plantas daninhas, com auxílio de técnicas convencionais, como das malhas amostrais, ou até mesmo avançadas, como a utilização de sensores para identificação.

Pulverizações dirigidas para controle de plantas daninhas proporcionam, além de economia de herbicidas, a harmonização das questões ambientais. Segundo trabalhos de Nuspl et al. [4] e Heisel et al. [5], a economia obtida na quantidade de herbicida 
aplicado varia de 30 a $80 \%$ e 66 a 75\%, respectivamente, devido à pulverização dirigida, comparada à pulverização em área total.

No entanto, são pouco conhecidos os métodos eficazes, rápidos e de baixo custo para levantamento das plantas daninhas. Dentro dos métodos convencionais das malhas amostrais para o levantamento, o tamanho da malha amostral afeta no tempo, trabalho e principalmente na precisão da análise da variabilidade das plantas daninhas.

Nordmeyer et al. [6] utilizou malha amostral de $30 \times 30 \mathrm{~m}$ para mapeamento de plantas daninhas em área de 13 ha. Gerhards et al. [7], para mapeamento de plantas daninhas para aplicação em pós-emergência, utilizou malha de 7 x 7 m. Já Lutman \& Perry [8] consideram 6 x $6 \mathrm{~m}$ o máximo de uma malha amostral para levantamento de plantas daninhas.
Neste sentindo, o presente trabalho teve como objetivo realizar o levantamento da variabilidade espacial da distribuição da planta daninha azevém em cultivo da cultura do trigo, com diferentes tamanhos de malhas amostrais e sua precisão de levantamento.

\section{Metodologia}

O experimento foi conduzido no município de Santa Maria, RS, localizado na Universidade Federal de Santa Maria (UFSM), área conhecida como "Área Nova", (Figura 1), com coordenadas geográficas $29^{\circ} 43^{\prime} 05^{\prime \prime} \mathrm{S}$ e $53^{\circ} 44^{\prime} 15^{\prime \prime} \mathrm{O}$, e altitude média de $115 \mathrm{~m}$.

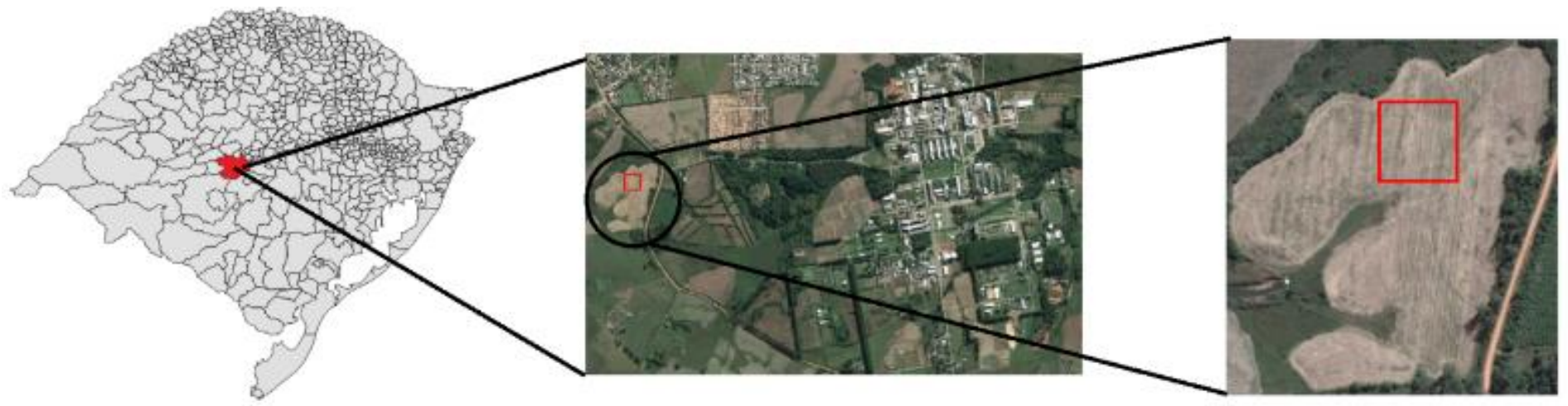

Figura 1. Localização da área experimental. Adaptado da base de dados do Google Earth e uso de arquivo shapefile do IBGE.

O solo predominante da área é o Argissolo Vermelho Distrófico típico, segundo a Embrapa [9]. O clima da região é classificado como Cfa [10], com temperatura média de $19,3^{\circ} \mathrm{C}$ e precipitação média anual de $1688 \mathrm{~mm}$.

A área agrícola do estudo estava sob desenvolvimento da cultura do trigo, em sucessão da cultura da soja, a qual foi colhida em 25 de março de 2017. Já a semeadura do trigo foi realizada em 20 de junho de 2017. Dentro dessa área total, foi selecionada uma área de 1 hectare, com lados de $100 \times 100$ m, para compor o experimento.

Foram geradas cinco malhas amostrais de plantas daninhas, utilizando o software Quantum GIS [11], com dimensões de 6,125 x $6,125 \mathrm{~m}, 12,5 \times 12,5 \mathrm{~m}, 25 \times 25 \mathrm{~m}, 50 \times 50 \mathrm{~m}$, e 100 x $100 \mathrm{~m}$, compondo $256,64,16,4$ e 1 pontos amostrais, respectivamente. Os pontos foram carregados para um receptor GNSS de navegação, marca Garmin ${ }^{\circledR}$, modelo GPSMap 62, com intuito de realizar a avaliação da distribuição e densidade de plantas daninhas. $\mathrm{O}$ erro de posição durante a coleta dos dados variou de 3 a $6 \mathrm{~m}$.

A avaliação de levantamento da população da planta daninha azevém na cultura do trigo foi realizada com o auxílio de quadrados amostrais metálicos com dimensão de $1 \mathrm{~m}^{2}$, que eram lançados sobre a cultura do trigo para se fazer a contagem de plantas de azevém, juntamente com o receptor GNSS, que indicava os pontos a serem mapeados, realizando a contagem visual e anotação em planilhas. O levantamento foi realizado quando a cultura do trigo se apresentava no início do afilhamento [12].

Os dados foram submetidos à análise estatística descritiva, utilizando o software R [13]. As análises da variabilidade espacial das distribuições da planta daninha azevém foram analisadas a partir da geoestatística realizada apenas para a malha de $6,125 \mathrm{x}$ $6,125 \mathrm{~m}$ ( 256 pontos), e 12,5 x 12,5 m (64 pontos), devido ao baixo número de pontos das outras malhas amostrais. Para as malhas 25 x $25 \mathrm{~m}$, e 50 x $50 \mathrm{~m}$, foi utilizada a técnica do inverso do quadrado da distância como interpolador. No método do inverso do quadrado da distância, o fator de ponderação, como o nome já indica, é o inverso do quadrado da distância euclidiana entre o ponto conhecido e o estimado. Esse método é considerado simples e de fácil aplicação, no entanto, menos acurado que a krigagem, uma vez que não considera o padrão da estrutura da dependência espacial $[14,15]$. Entretanto, Couto et al. [16] relataram que tanto a krigagem como o inverso do quadrado da distância apresentam destaque de utilização na inferência de dados.

Do ajuste de um modelo matemático aos dados foram definidos os parâmetros do semivariograma: efeito pepita $(\mathrm{C} 0)$, 
contribuição (C1) e alcance (a). Para análise do índice de dependência espacial (IDE), foi utilizada a relação $\mathrm{C} 1 /(\mathrm{C} 0+$ C1)*100, com os intervalos: dependência espacial fraca (IDE < $25 \%$ ); moderada $(25 \% \leq \mathrm{IDE}<75 \%$ ) e forte (IDE $\geq 75 \%)$, [17].

A similaridade dos mapas temáticos de azevém, construídos a partir dos dados coletados nas diferentes malhas amostrais, foi avaliada por meio de dois parâmetros estatísticos: correlação linear de Pearson e coeficiente de desvio relativo (CDR). O CDR expressa a diferença média, em módulo, dos valores interpolados em cada mapa, considerando um deles como mapa referência (padrão). Quanto menor for o percentual encontrado, maior será a similaridade entre os mapas [18].

O cálculo é dado pela equação adaptada de Coelho et al. [19], $C D R=\sum \mid($ Dij - Diref $) /$ Diref $\mid \times(100 / n)$, em que: n é o número de pontos interpolados $(\mathrm{n}=256$ pontos); Diref é a densidade referência da planta daninha no ponto i, sendo que as densidades de referência da planta daninha foram obtidas na malha mais densa de 6,125 x 6,125 m; e Dij é a densidade de azevém no ponto i para as diferentes dimensões de malhas amostrais j (j1, $12,5 \times 12,5$ m; j2, $25 \times 25$ m; j3, $50 \times 50$ m; j4, $100 \times 100$ m).

\section{Resultados e discussões}

Pode-se observar que no levantamento da distribuição e densidade da planta daninha azevém, nas malhas amostrais 6,125 x 6,125 m, 12,5 x 12,5 m, 25 x 25 m e 50 x 50 m, com exceção da malha 100 x $100 \mathrm{~m}$, obteve-se diferença nos números de plantas encontradas e tendências de distribuições (Figura 2).
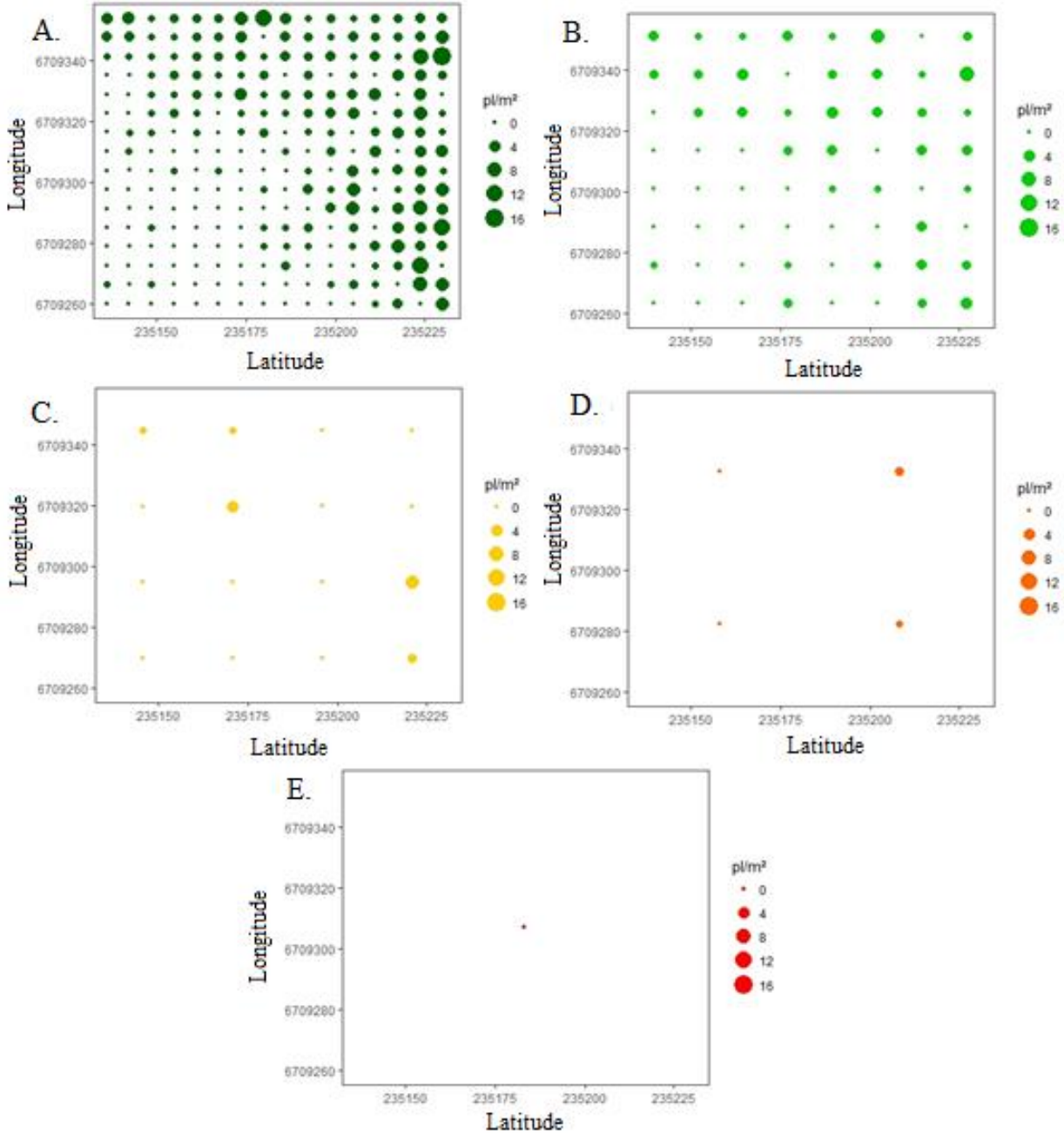

Figura 2 - Distribuição da densidade de plantas de azevém nas diferentes dimensões de malhas amostrais.

Legenda: pl $\backslash \mathrm{m}^{2}=$ plantas observadas no ponto amostral por $\mathrm{m}^{2}$; A. = malha amostral de dimensão 6,125 x 6,125 m; B.= 12,5 x $12,5 \mathrm{~m} ; \mathrm{C} .=25 \times 25 \mathrm{~m} ; \mathrm{D} .=50 \mathrm{x}$ $50 \mathrm{~m} \mathrm{e} \mathrm{E.}=100 \times 100 \mathrm{~m}$. 


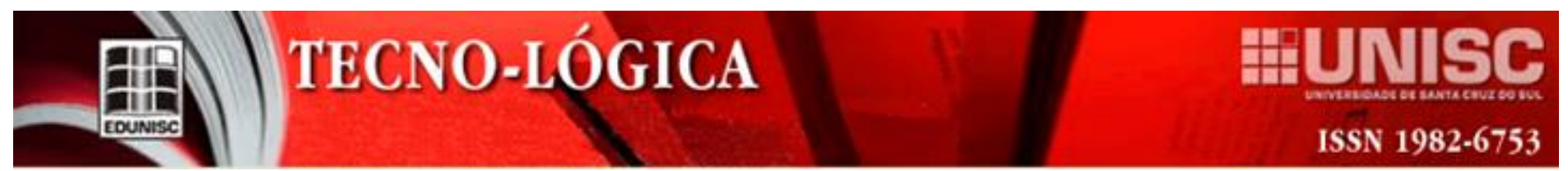

Também foi observado que apresentaram elevada dispersão relativa em relação à média, verificado pelos valores dos coeficientes de variação (CV), variando de 121,29 e $207,82 \%$ (Tabela 1). Observação que caracteriza a heterogeneidade de sua presença e grau de infestação na área, variando de 0 a 16; 0 a 8; 0 a 7; 0 a 2; e apenas 0 plantas $\mathrm{m}^{2}$, nas respectivas malhas amostrais citadas acima.

Tabela 1 - Análise estatística descritiva da distribuição da planta daninha azevém utilizando diferentes dimensões de malhas amostrais.

\begin{tabular}{cccccc}
\hline \multirow{2}{*}{$\begin{array}{c}\text { Parâmetros } \\
\text { estatísticos }\end{array}$} & $\mathbf{6 , 1 2 5} \mathbf{x}$ & $\mathbf{1 2 , 5} \mathbf{x}$ & $\mathbf{2 5} \mathbf{x}$ & $\mathbf{5 0} \mathbf{x}$ & $\mathbf{1 0 0} \mathbf{x}$ \\
& $\mathbf{6 , 1 2 5 m}$ & $\mathbf{1 2 , 5 m}$ & $\mathbf{2 5 m}$ & $\mathbf{5 0 m}$ & $\mathbf{1 0 0 m}$ \\
\hline Número de amostras & 256 & 64 & 16 & 4 & 1 \\
Mínimo & 0 & 0 & 0 & 0 & 0 \\
Máximo & 16 & 8 & 7 & 2 & 0 \\
Média & 1,60 & 1,39 & 0,94 & 0,75 & 0,00 \\
Moda & 0 & 0 & 0 & 0 & 0 \\
Desvio Padrão & 2,28 & 1,69 & 1,95 & 0,96 & - \\
CV* (\%) & 142,6 & 121,3 & 207,8 & 127,7 & - \\
Assimetria & 0,70 & 0,82 & 0,48 & 0,78 & - \\
Curtose & 0,25 & 0,33 & 0,17 & 0,37 & - \\
\hline
\end{tabular}

* Coeficiente de variação (\%).

Ainda é possível evidenciar que, a partir do levantamento, verificou-se que, na maioria das vezes, não foi encontrada a planta daninha em questão, retratado pela caracterização da moda ser igual a 0 em todas as malhas amostrais. A média da população de azevém encontrada na área decaiu gradualmente em função do aumento do tamanho da grade amostral, tendo na grade de $100 \mathrm{x}$ $100 \mathrm{~m}$, segundo o levantamento, ausência da planta daninha.

O modelo pelo qual os semivariogramas foram melhores ajustados foi o gaussiano. O alcance, considerado como distância limite de dependência espacial, segundo Vieira et al. [20], pode auxiliar na escolha de uma malha amostral, em que a distância máxima entre pontos amostrais forneça dados confiáveis da densidade de plantas daninhas. $O$ alcance determinado pela geoestatística da avaliação da malha amostral 6,125 x 6,125 m foi de $123,18 \mathrm{~m}$, enquanto que a malha amostral $12,5 \times 12,5 \mathrm{~m}$ apresentou valor de $109,44 \mathrm{~m}$. Os IDE para as malhas $6,125 \mathrm{x}$ $6,125 \mathrm{~m}$ e 12,5 x 12,5 m foram de 86,97 e 74,48\%, enquadrandose como forte e moderada dependência espacial, respectivamente.

Em relação aos resultados do CDR (Figura 3), verificou-se a variação crescente de valores, de $48,43 \%$ para a malha $12,5 \mathrm{x}$ $12,5 \mathrm{~m}$, à 68,20 \% para a malha 100 x $100 \mathrm{~m}$. Isso evidencia que, conforme aumenta o tamanho da malha amostral e, em consequência, a distância entre os pontos amostrais, há aumento do CDR, relativo a menor malha amostral $(6,125$ x 6,125 m), a qual foi predefinida como referência para o cálculo.

Há resultados que corroboram com malhas amostrais de mapas de produtividade de soja [19] e de milho [21]. Resultados semelhantes, como o trabalho de Cherubin et al. [18] com diferentes tamanhos de malhas amostrais para caracterizar a variabilidade espacial de fósforo e potássio em Latossolo Vermelho.

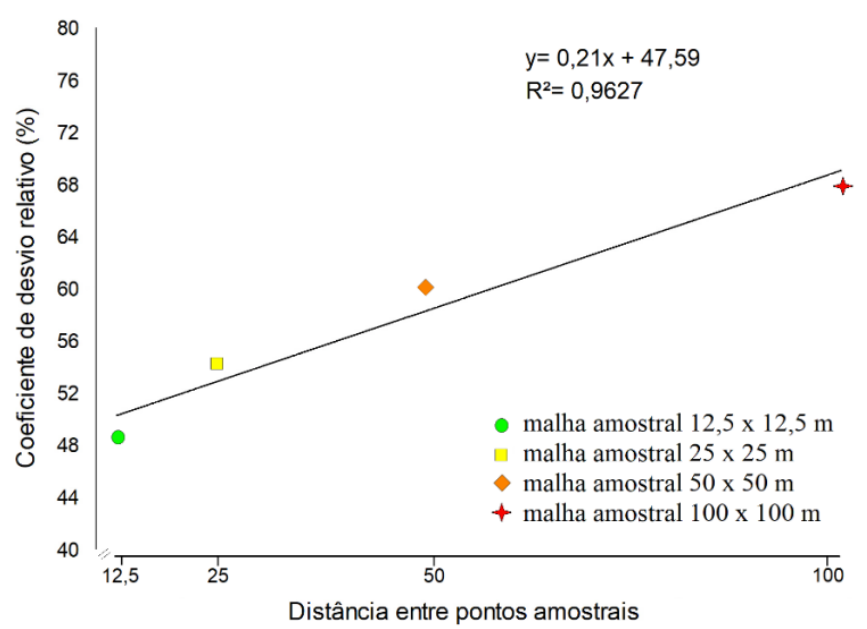

Figura 3 - Coeficientes de desvio relativo (CDR) do levantamento da planta daninha azevém nas diferentes dimensões de malhas amostrais.

Esses resultados são indicativos de que o CDR é um parâmetro eficiente para avaliar a similaridade dos mapas temáticos de planta daninha.

Outro parâmetro estatístico utilizado foi a correlação linear de Pearson, a qual foi significativa a $5 \%$ de probabilidade apenas na correlação da malha 6,125 x 6,125 m, com a 12,5 x 12,5 m com $\mathrm{r}=0,41$ (Tabela 2). Houve correlação positiva da malha referência com as malhas $25 \times 25 \mathrm{~m}, 50 \times 50 \mathrm{~m}$, porém sem significância expressiva. No restante, a correlação é praticamente nula.

Tabela 2 - Análise de correlação linear de Pearson

\begin{tabular}{ccccc}
\hline & \multicolumn{4}{c}{ Malha amostral } \\
\cline { 2 - 5 } Malha amostral & $\mathbf{6 , 1 2 5} \times$ & $\mathbf{1 2 , 5} \times$ & $\mathbf{2 5} \times$ & $\mathbf{5 0} \times$ \\
& $\mathbf{6 , 1 2 5 m}$ & $\mathbf{1 2 , 5 m}$ & $\mathbf{2 5 m}$ & $\mathbf{5 0 m}$ \\
\hline $\mathbf{6 , 1 2 5} \times \mathbf{6 , 1 2 5 m}$ & 1 & & & \\
$\mathbf{1 2 , 5} \times \mathbf{1 2 , 5 m}$ & $0,41^{*}$ & 1 & & \\
$\mathbf{2 5} \times \mathbf{2 5 m}$ & 0,22 & 0,03 & 1 & \\
$\mathbf{5 0} \times \mathbf{5 0 m}$ & 0,19 & 0,04 & 0,09 & 1 \\
\hline
\end{tabular}

* Significativo pela correlação linear de Pearson, a 5\% de probabilidade. $\mathrm{n}=256$.

Os resultados obtidos inferem que, à medida que se aproximam os pontos amostrais, mais acurados são os valores dos locais não amostrados estimados por interpoladores geoestatísticos [19]. Espera-se, no entanto, que os pontos de amostragens localizados mais próximos sejam mais parecidos entre si do que os mais afastados, o que reduziria a probabilidade de erros [22], sobretudo na confecção de mapas temáticos (Figura 4). 

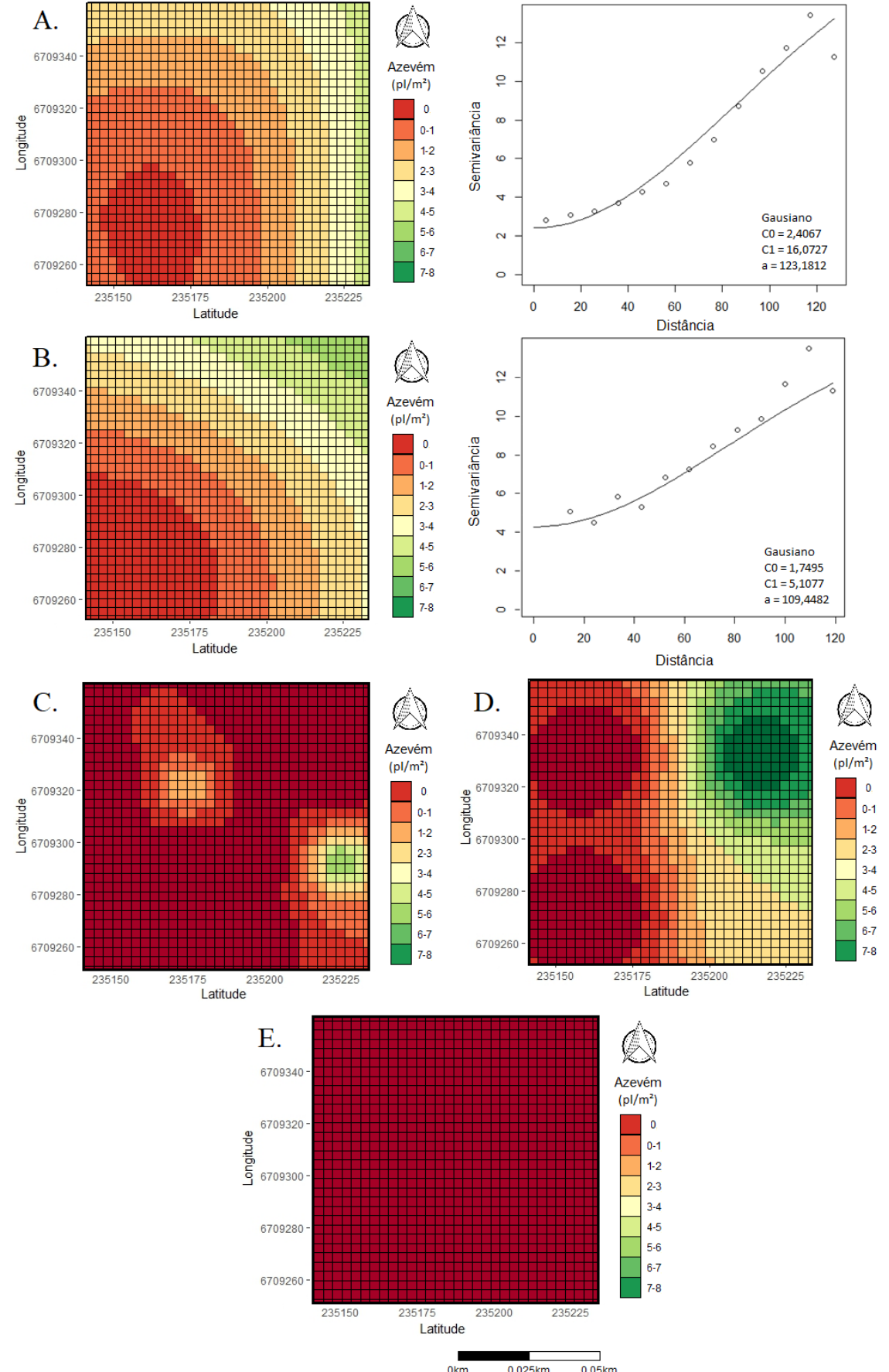

Figura 4 - Mapa temático da densidade de plantas de azevém obtida pela malha amostral. A.= malha amostral de dimensão $6,125 \times 6,125 \mathrm{~m} ; \mathrm{B} .=12,5 \times 12,5 \mathrm{~m} ; \mathrm{C} .=25 \mathrm{x}$ $25 \mathrm{~m} ; \mathrm{D} .=50 \times 50 \mathrm{~m} \mathrm{e} \mathrm{E.}=100 \times 100 \mathrm{~m}$.

Legenda: $\mathrm{pl} \backslash \mathrm{m}^{2}=$ plantas observadas no ponto amostral por $\mathrm{m}^{2}$. 
Também é notório que, da mesma forma que diminui o tamanho da malha amostral, ou seja, aumenta o número de pontos por área, aumenta o tempo necessário para executar o levantamento, onerando o levantamento da forma convencional.

Estudos com sensores de plantas daninhas com objetivo de identificá-las têm sido recorrentes na bibliografia recente. Herrmann et al. [23] utilizaram sensores ópticos para detectar plantas daninhas na cultura do trigo. Ainda, Safanelli et al. [24] caracterizaram comprimentos de onda com maior amplitude de diferenciação da planta daninha Euphorbia heterrophilla (L.) na cultura da soja.

Com vista da variabilidade espacial da densidade de azevém como planta daninha, reforça as afirmações da utilização de ferramentas de agricultura de precisão para realizar levantamento de problemas fitossanitários de forma georreferenciada e realizar manejo em sítio-específico, podendo reduzir a quantidade de agrotóxicos utilizados no sistema de produção agrícola, trazendo benefícios ambientais.

\section{Conclusões}

A redução do tamanho da malha amostral aumenta a precisão na caracterização da variabilidade espacial de densidade da planta daninha azevém através de mapas temáticos.

A utilização da malha amostral de dimensão 6,125 x 6,125 $\mathrm{m}$ apresenta maior detalhamento da variabilidade espacial de azevém em área de cultivo de trigo, comparada a maiores tamanhos de malhas amostrais. No entanto, são necessários maior tempo e trabalho no levantamento.

O levantamento da densidade de planta daninha azevém permite a confecção de mapas temáticos que possibilitam o controle em sítio-específico da mesma na cultura do trigo.

\section{Agradecimentos}

O presente trabalho foi realizado com apoio da Coordenação de Aperfeiçoamento de Pessoal de Nível Superior Brasil (CAPES) - Código de Financiamento 001.

\section{SPATIAL VARIABILITY OF RYEGRASS IN WHEAT CULTIVATION USING DIFFERENT SAMPLE GRIDS}

ABSTRACT: In recent years, the main weed of the wheat crop has been the ryegrass, which infests wheat crop and competes for natural resources. The control of weeds, in general, is carried out indiscriminately, not taking into account their spatial variability. One way to accurately map weeds is to use sample grids. The objective of this study was to evaluate the spatial variability of ryegrass distribution with different sample grid sizes. Five sample grids with dimensions of $6.125 \times 6.125 \mathrm{~m}, 12.5 \times 12.5 \mathrm{~m}, 25 \times 25$ $\mathrm{m}, 50 \times 50 \mathrm{~m}$, and $100 \times 100 \mathrm{~m}$ were generated. The evaluation of the mapping of the ryegrass population was carried out with metallic sampling squares, when the wheat was at the beginning of the tillering stage. Sample grids of $6.125 \times 6.125 \mathrm{~m}, 12.5 \times 12.5$ $\mathrm{m}, 25 \times 25 \mathrm{~m}$ and $50 \times 50 \mathrm{~m}$, except for the $100 \times 100 \mathrm{~m}$ grid, presented a high coefficient of variation, which characterizes the heterogeneity of its presence and population and the degree of infestation in the area. It is concluded that the size reduction of the sample grid increases the precision in the characterization of the spatial variability of weed density, making it possible to produce thematic maps of the ryegrass infestation with precision.

Keywords: Precision agriculture. geostatistics. thematic maps.

\section{Referências}

[1] CONAB. Acompanhamento da safra brasileira de grãos: Vol. 6 n. 3. - Safra 2018/19- terceiro levantamento. Disponível em:< file://C:/Users/Cliente/Downloads/BoletimZGraosZdezembroZ2018.pdf〉. Acesso em 15 dez. 2018.

[2] LAMEGO, F. P.; KASPARY, T. E.; RUCHEL, Q.; GALLON, M.; BASSO, C. J.; SANTI, A. L. Habilidade competitiva de cultivares de trigo com plantas daninhas. Planta Daninha, Vol. 31, p. 521-531, 2013.

[3] HEAP, I. The International Survey of Herbicide Resistant Weeds. 2017. Disponível em: <http://www.weedscience.org/Summary/Species.aspx >. Acessado em: 23 de novembro de 2018.

[4] NUSPL, S. J.; RANDOLF, W. W.; GUTHLAND, R. Use of injection for sitespecific chemical application. In: PROCEEDINGS OF THE THIRD INTERNATIONAL CONFERENCE ON PRECISION AGRICULTURE, Minneapolis, MM. 23-26 jun. 1996.

[5] HEISEL, T.; ANDREASEN, C.; ERSBOLL, A. K. Annual weed densities can be mapped with kriging. Weed Research, Vol. 36, p. 325-337, 1996.

[6] NORDMEYER, H.; HÄUSLER, A.; NIEMANN, P. Patchy weed control as an approach in precision farming. In: EUROPEN CONFERENCE ON PRECISION AGRICULTURE 97, 1., 1997, Warwick Proceedings.... London: BIOS Scientific Publications, p. 307-314, 1997.

[7] GERHARDS, R. et al. Spatial Stability of weed patches in agricultural fields. In: THE INTERNATIONAL CONFERENCE ON PRECISION AGRICULTURE Proceedings. Wisconsin: ASA: CSSA: SSSA, p. 495-504, 1996.

[8] LUTMAN, P. J. W.; PERRY, N. H. Methods of weed patch detection in cereal crops. In: THE BRIGHTON CONFERENCE- WEEDS, Brighton, 1999. Anais Brighton, p. 627-634, 1999.

[9] SANTOS, H. G.; JACOMINE, P. K. T.; ANJOS, L. H. C.; OLIVEIRA, V. A.; LUMBRERAS, J. F.; COELHO, M. R.; ALMEIDA, J. A.; CUNHA, T. J. B.; OLIVEIRA, J. B. Embrapa: Sistema Brasileiro de Classificação de Solos. $3^{\text {a }}$ ed, Brasília, 2013.353p.

[10] ALVARES, C.A.; STAPE, J.L.; SENTELHAS, P.C.; DE MORAES GONÇALVES, J.L.; SPAROVEK, G. Köppen's climate classification map for Brazil. Meteorologische Zeitschrift, Vol. 22, p. 711-728, 2013.

[11] QGIS DT. Geographic Information System. Open Source Geospatial Foundation Project. $2018 . \quad$ Disponível em: 
<https://www.qgis.org/pt_BR/site/forusers/download.html>. Acessado em 12 de dezembro de 2018.

[12] LARGE, E. C. Growth stages in cereals. Illustration of the Feekes Scale. Plant Pathology, London, Vol. 3, p. 128-129, 1954.

[13] R DEVELOPMENT CORE TEAM. R: A Language and Environment for Statistical Computing. Vienna, R Foundation for Statistical Computing. 2018. Disponível em: <https://www.r-project.org/>. Acessado em: 01 jan. 2019.

[14] MELLO, C. R.; LIMA, J. M.; SILVA, A. M.; MELLO, J. M.; OLIVEIRA, M. S. Krigagem e inverso do quadrado da distância para interpolação dos parâmetros da equação de chuvas intensas. Revista Brasileira de Ciência do Solo, Vol. 27, n. 5, p. $925-933,2003$

[15] SOUZA, G. S.; LIMA, J. S. S.; XAVIER, A. C.; ROCHA, W. S. D. Krigagem ordinária e inverso do quadrado da distância aplicados na espacialização de atributos químicos de um Argissolo. Scientia Agraria, Vol. 11, p. 73-81, 2010.

[16] COUTO, E. G.; SCARAMUZZA, J. F.; MARASCHINI, L. Influência dos métodos de interpolação dos dados nos mapas usados na agricultura de precisão. In: SIMPÓSIO INTERNACIONAL DE AGRICULTURA DE PRECISÃO, Viçosa. Anais, SIAP, p. 1-5, 2002.

[17] ZIMBACK, C.R.L. Análise especial de atributos químicos de solos para fins de mapeamento da fertilidade. 2001. 114f. Tese (Livre-Docência em Levantamento do solo e fotopedologia) - FCA-UNESP, Botucatu, SP. 2001.

[18] CHERUBIN, M. R.; SANTI, A. L.; EITELWEIN, M. T.; AMADO, T. J. C.; SIMON, D. H.; DAMIAN J. M. Dimensão da malha amostral para caracterização da variabilidade espacial de fósforo e potássio em Latossolo Vermelho. Pesquisa Agropecuária Brasileira, Vol. 50, p. 168-177, 2015.

[19] COELHO, E. C.; SOUZA, E. G.; URIBE-OPAZO, M. A.; PINHEIRO, N. R. Influência da densidade amostral e do tipo de interpolador na elaboração de mapas temáticos. Acta Scientiarum. Agronomy, Vol. 31, p. 165-174, 2009.

[20] VIEIRA, S. R.; MILLETE, J.; TOPP, G. C.; REYNOLDS, W. R. Handbook for geostatistical analysis of variability in soil and climate data. In: Alvarez, V. V. H.; Schaefer, C. E. G. R; Barros, N. F.; Mello, J. W. V.; Costa, L. M. Tópicos em ciência do solo. Viçosa, $2^{\circ}$ Volume da UFV, p. 1-46, 2002.

[21] SPEZIA, G. R.; SOUZA, E. G.; NÓBREGA, L. H. P.; URIBE-OPAZO, M. A.; MILAN, M.; BAZZI, C. L. Model to estimate the sampling density for establishment of yield mapping. Revista Brasileira de Engenharia Agrícola e Ambiental, Vol. 16, n. 4, p. 449-457, 2012.

[22] WEBSTER, R.; LARK, M. Field sampling for environmental science and management. London: Routledge, 2012. 200p.

[23] HERMANN, I.; SHAPIRA, U.; KINAST, S.; KARNIELI, A.; BONFIL, D. J. Ground-level hyperspectral imagery for detecting weeds in wheat fields. Precision Agriculture, Vol. 14, p. 637-659, 2013.

[24] SAFANELLI, J. L.; BOESING, B. F. B.; BOTEGGA, E.; CATEN, A. T. L. Diferenciação de Euphorbia heterophylla L. em lavoura de soja utilizando espectrorradiometria. In: XXVI CONGRESSO BRASILEIRO DE CARTOGRAFIA, $\mathrm{V}$ CONGRESSO BRASILEIRO DE GEOPROCESSAMENTO, XXV Exposicarta, Gramado RS. Anais p. 1-6, 2014. 